\title{
Hot topic: Brown marmorated stink bug odor compounds do not transfer into milk by feeding bug-contaminated corn silage to lactating dairy cattle
}

\author{
R. L. Baldwin VI, ${ }^{\star 1}$ A. Zhang,† S. W. Fultz,‡ S. Abubeker,† C. Harris,† E. E. Connor, ${ }^{\star}$ and D. L. Van Hekken§ \\ *Bovine Functional Genomics Laboratory, and \\ †Invasive Insect Biocontrol and Behavior Laboratory, USDA, Agricultural Research Service, Beltsville, MD 20705 \\ łUniversity of Maryland (UMD) Extension, Frederick 21702 \\ §Dairy and Functional Foods Research Unit, USDA, Agricultural Research Service, Wyndmoor, PA 19038
}

\section{ABSTRACT}

Brown marmorated stink bug (BMSB; Halyomorpha halys) is an emerging invasive species of grave concern to agriculture as a polyphagous plant pest with potential negative effects on the dairy industry. The purpose of this study was to determine the risk of including BMSB-contaminated silage in lactating dairy cow rations. First, 6 dairies, either highly infested (n $=3 ; 30$ to 100 bugs per stalk) or not infested ( $\mathrm{n}=$ 3 ), were sampled to assess the prevalence of bug secretion compounds tridecane (major component) and E-2-decenal (stink odor component) in silage and milk. Second, using wild BMSB, a mini-silo dose-response experiment (adding 100, 50, 25, 10, and 1 freshly crushed bugs $/ 0.5 \mathrm{~kg}$ of chopped corn) was conducted to assess the effect of ensiling on BMSB stink odor compounds. Finally, synthetic BMSB stink odor compounds (10 g of tridecane and $5 \mathrm{~g}$ of $E$-2-decenal) were ruminally infused twice daily over $3 \mathrm{~d}$, and samples of milk, urine, and rumen fluid were collected to evaluate disposition. Bug stink odor compounds were sampled by solid-phase microextraction (SPME) and analyzed by gas chromatography-mass spectrometry (GC-MS). Milk production and feed composition were unaffected when BMSB-contaminated silage was fed. Moreover, no $E$-2-decenal was detected in silage or milk (detection threshold $=0.00125 \mu \mathrm{g} / \mathrm{mL}$ ). The dose-response of tridecane in mini-silo samples exhibited a linear relationship $\left(\mathrm{R}^{2}=0.78\right)$ with the amount of BMSB added; however, E-2-decenal was completely decomposed and undetectable in spiked mini-silos after ensiling. Both synthetic secretion compounds infused into rumen were undetectable in all milk and urine samples. E2-Decenal was not detectable in rumen fluid, whereas tridecane was detected only at 15 min postinfusion but not present thereafter. Feed intake was unaffected by infusion treatment and BMSB secretion compounds

Received September 30, 2013

Accepted January 25, 2014.

${ }^{1}$ Corresponding author: ransom.baldwin@ars.usda.gov
(E-2-decenal and tridecane) were not observed in milk. $E$-2-Decenal and tridecane from the metathoracic gland of BMSB are not able to contaminate milk either due to the ensiling process or because of metabolism within the rumen. Concern over BMSB stink odor compounds contaminating the fluid milk supply, even on highly infested farms, is not warranted.

Key words: dairy cow, brown marmorated stink bug, milk, stink bug odor

\section{Hot Topic}

The brown marmorated stink bug (BMSB), Halyomorpha halys, is an invasive insect pest introduced into the United States from its native range in Japan, Korea, and China. The BMSB was first identified in 2001 in Allentown, Pennsylvania, but is believed to have been introduced as early as 1996 (Hoebeke and Carter, 2003; Hamilton, 2009), possibly through the movement of bulk containers (Hamilton, 2009). Since that time, it has spread to multiple states in the continental United States and Canada (Wermelinger et al., 2008). Currently, BMSB has established populations on both coasts but is most widely spread in the midAtlantic region (Leskey et al., 2012).

In addition to the economic impact of this pest, BMSB is a nuisance pest for businesses and homeowners. It overwinters as an adult, aggregating in high numbers when seeking shelter (Hoebeke and Carter, 2003), usually on the sides of buildings, garages, and other structures (Hamilton, 2009). The population size of BMSB has steadily grown in the United States since its introduction. Although lower levels of economic damage were observed as early as 2002 in Pennsylvania (Bernon, 2004), documentation of greater damage appeared in 2006, when BMSB first caused major economic damage (Nielsen et al., 2008; Hamilton, 2009). During the 2009 growing season, serious economic injury to several crops, including peach, apple, and Asian pear, was reported due to large BMSB populations (USDA-ARS, 2010). 
During the 2010 growing season, significant damage occurred throughout the mid-Atlantic area to the crops listed above as well as field corn, sweet corn, soybeans, brambles, and grapes. Populations of BMSB as high as 100 per corn stalk were reported in the Middletown and Burkittsville areas of Maryland. Harvested corn silage had the distinctive BMSB odor, and dairy producers were concerned about the effect on feed quality and the subsequent milk produced from this feed. Milk contaminated with BMSB off-flavors could have a devastating effect on the fluid milk industry. A literature review found no published information on the effect of stink bugs in milk. If dairy feed is contaminated with BMSB odor-causing compounds, it could result in contaminated milk. Therefore, the objective of these studies was to assess if the odor-causing compounds secreted by BMSB were stable enough to transfer through the harvesting, processing, ensiling, feeding, and digestion processes and, ultimately, to contaminate milk.

To identify the BMSB effluvial odor, volatiles were collected using 3 groups of males, females, and nymphs (12 insects per group, 40-d-old males and females, 4 to 5 stages of nymphal instars) at room temperature. The bugs were separately introduced into three 1-L, 4-necked glass containers (Zhang et al., 1994). Air was drawn into the container through 6- to 14-mesh activated charcoal (Fisher Scientific, Pittsburgh, PA) and out of the container through 2 traps $(15 \mathrm{~cm} \times 1.5-$ cm o.d.) containing Super Q adsorbent (200 mg each; Alltech Associates Inc., Deerfield, IL) by vacuum ( 1 $\mathrm{L} / \mathrm{min}$ ). Insects were fed with organic green beans and aerated continuously for $24 \mathrm{~h}$ at room temperature with a $16 \mathrm{~h}$ light:8 h dark photoperiod. Adsorbents were eluted with methylene chloride $(4 \times 0.5 \mathrm{~mL})$; then, the eluates $(2 \mathrm{~mL} /$ sample) were concentrated to $\sim 200$ $\mu \mathrm{L}$ under a nitrogen stream and stored at $-30^{\circ} \mathrm{C}$ for future analysis. The headspace collection result showed that adult male BMSB released 4 compounds as major volatile emissions (Figure 1). The volatiles from females and nymphs were very similar to the adult male emission. The major compound, tridecane (peak 3 in Figure 1 ), is a chemically stable compound that is odorless and may simply serve as a solvent or spreading agent for the more irritating compounds. Another major compound, $E$-2-decenal (peak 2 in Figure 1), is the major irritant and responsible for the potent stink odor from BMSB. However, being an extremely unstable compound it can easily break down, and the degradation products do not have the distinctive BMSB odor. These 2 major components make up more than $70 \%$ of the total volatile emission and therefore were selected as target molecules to evaluate the effect of BMSB on feed quality and the subsequent milk produced. In this study, 3 independent approaches were used to assess the potential for an ef- fect on (1) fluid milk quality in conventional production setting with or without contaminated corn fields, (2) resilience of the bug stink odor compounds through ensiling, and (3) the extent to which compounds directly infused ruminally can be observed in body fluids.

In the first approach, a farm survey using 6 farms self-reporting either high or low BMSB infestations in corn crops at harvest were selected, and monthly samples of silage and milk were collected from May to October 2011. Silage and milk samples from these farms were submitted to a commercial laboratory (Cumberland Valley Analytical Services, Hagerstown MD) for standard composition analysis. In addition, raw, fresh milk samples were collected and analyzed for the presence of $E$-2-decenal and tridecane using solidphase microextraction (SPME) and GC-MS.

The second approach assessed the effect of ensiling on odor compounds in silage. Adult and late instar BMSB were collected by hand from a sweet corn crop in Burrittsville, Maryland, over a 3-d period (August 30 to September 1, 2011). Insects were collected and kept with sweet corn as a feed source in a $23.2 \mathrm{~cm} \times$ $16.8 \mathrm{~cm} \times 15.24 \mathrm{~cm}$ plastic pet keeper (Small Petco Pet Keeper, International Pet Supplies and Distributors, San Diego, CA). Fresh corn silage for the mini-silo experiment was collected from a farm in Middletown, Maryland, at the time of corn chopping and trench silo filling. The field was scouted and no BMSB were found before or during chopping. Plant population was 38,768 plants/acre. Using an average plant population of 29,000 plants/acre, and a 16 ton/acre average yield (Maryland Ag Statistic 5-yr average; Maryland Department of Agriculture, 2004-2008), the number of BMSB required to equal $1,10,25,50$, and $100 \mathrm{BMSB}$ per stalk of corn was determined to be 1, 10, 25, 50, and 100 BMSB per $500 \mathrm{~g}$ of chopped material. Pet keepers used to hold bugs were placed into a chest freezer for $60 \mathrm{~s}$ to slow movement of the bugs for counting and distribution of treatments into the mini-silo bags. Using a stainless steel mortar and pestle (model 8395, Amco Houseworks, Vernon Hills, IL), BMSB were crushed and mixed in a shallow aluminum pan with $500 \mathrm{~g}$ of corn silage. Subsequently, the mixture was placed into a $20-\mathrm{cm} \times 38-\mathrm{cm}, 3$-mil polyethylene vacuum bag and sealed in a single chamber vacuum packaging machine (Koch Ultravac 500, Koch Equipment LLC, Kansas City, MO) set at $96 \%$ vacuum. Zero-time bags for each dose were immediately frozen. All other bags were placed into black plastic bags and allowed to ferment for $90 \mathrm{~d}$ at room temperature $\left(22^{\circ} \mathrm{C}\right)$ before freezing at $-20^{\circ} \mathrm{C}$ until analyzed by SPME GC-MS (Rasmussen et al., 1997; Zhang et al., 1999).

In the third and final approach, 5 ruminally fistulated Holstein dairy cows in mid-lactation were directly 


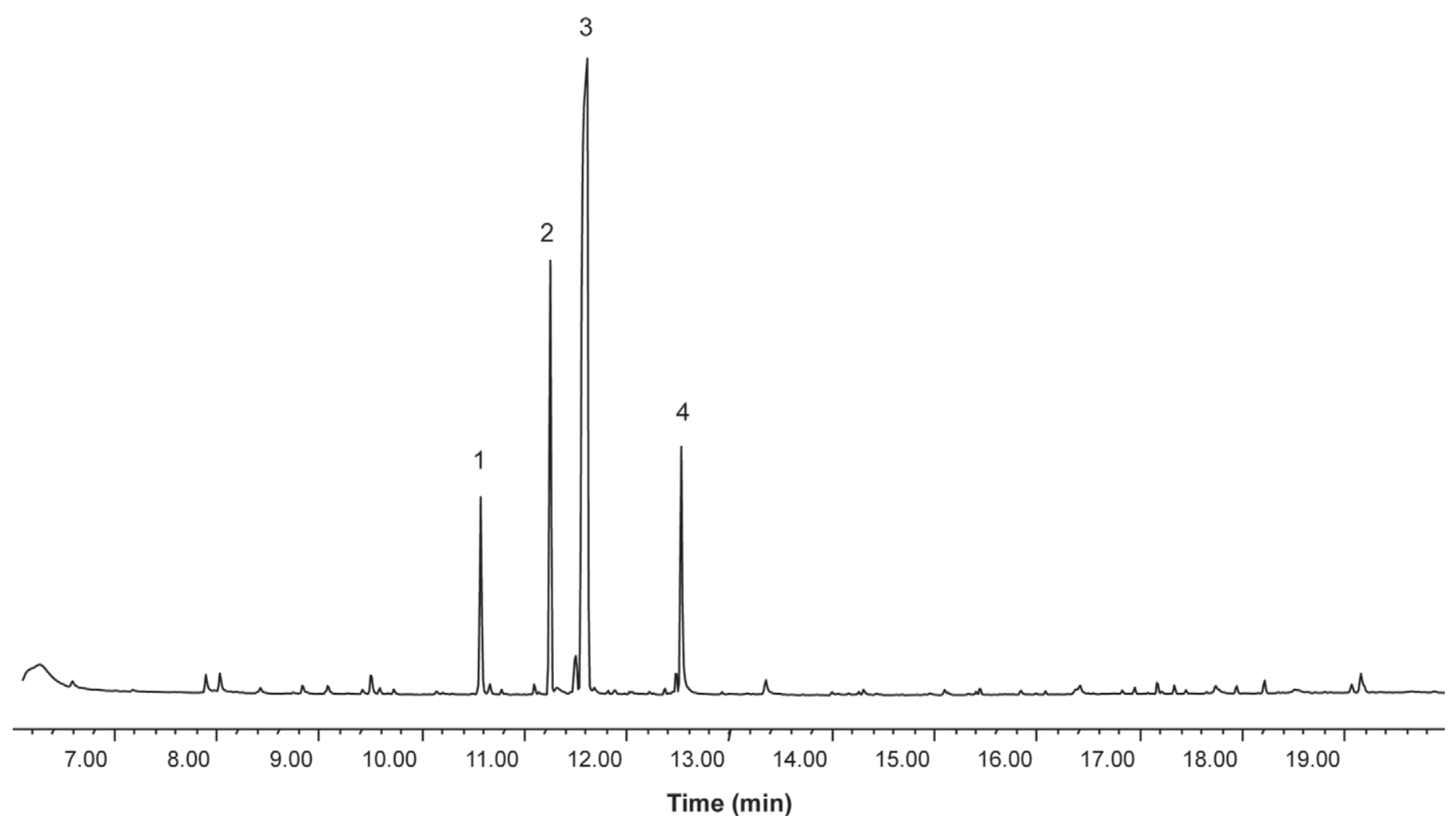

Figure 1. Gas chromatography-MS total ion chromatogram of volatile emission from adult male brown marmorated stink bugs (BMSB). Peak numbers correspond to dodecane (1), E-2-decenal (2), tridecane (3), and E-2-decenayl acetate (4).

infused with synthetic BMSB odor compounds ( $5 \mathrm{~g}$ of tridecane and $2.5 \mathrm{~g}$ of $E$-2-decenal) twice daily following milking. The dosage was determined based on the highest infestation reported of 100 bugs per corn plant and assumed no loss in harvest or processing; thus, it represents a very high dose to the cow. In addition to feed intake and production parameters, milk, rumen liquor, blood, urine, and fecal samples for SPME GC-MS analysis (Rasmussen et al., 1997; Zhang et al., 1999) for odor compounds were collected before dosing (d 1 to 3 ), and samples were subsequently collected at every milking for 1 wk to establish the dissipation pattern of the compounds. Samples were processed and frozen before analysis by SPME GC-MS.

The SPME GC-MS procedure was conducted at the Beltsville (Maryland) and Wyndmoor (Pennsylvania) laboratories using the same methodology. Briefly, elution times for tridecane and $E$-2-decenal were established by spiking commercial whole milk with tridecane (99.9\% purity) and E-2-decenal ( $>98 \%$ purity) standards (Sigma-Aldrich, St. Louis, MO). Standard curves were conducted for each compound (0.00125 to 0.05 $\mu \mathrm{g} / \mathrm{mL}$ in the milk) to determine the limit of detection (LOD) and limit of quantification (LOQ; Grob and Barry, 2004). Fresh milk samples from the farms were shipped overnight on ice packs, frozen immediately upon arrival at the Wyndmoor facility, and stored at $-80^{\circ} \mathrm{C}$ until analyzed. Aliquots $(10 \mathrm{~mL})$ of either the spiked milk or fresh farm milk were placed into $20-\mathrm{mL}$ vials and $4 \mathrm{~g}$ of $\mathrm{NaCl}$ was added. The samples were mixed at $500 \mathrm{rpm}$ and warmed to $40^{\circ} \mathrm{C}$. Headspace extraction using SPME was conducted by inserting a DVB/CAR/ PDMS (divinylbenzene/carboxen/polydimethylsiloxane) fiber (Supelco Inc., Bellefonte, PA) into the heated vials for 40 min while the milk sample was stirred. The SPME fiber was then placed in the injection port of the $\mathrm{GC}$ and held for $5 \mathrm{~min}$ at $250^{\circ} \mathrm{C}$ for desorption. The SPME fibers were conditioned between samples at $250^{\circ} \mathrm{C}$ for $20 \mathrm{~min}$ at the injection port.

A gas chromatograph (model 6890N; Agilent, Santa Clara, CA) fitted with a DB-5 MS capillary column $(30.0 \mathrm{~m} \times 0.25 \mathrm{~mm} \times 0.25 \mu \mathrm{m}$ film thickness; Agilent $)$ coupled to a mass spectrometer (model 5975, Agilent) and a Combipal autosampler (CTC Analytics AG, Zwingen, Switzerland) was used for GC-MS analyses. Analysis runs were conducted in splitless mode using He carrier gas at a flow rate of $0.6 \mathrm{~mL} / \mathrm{min}$. Oven temperature started at $40^{\circ} \mathrm{C}$ for $2 \mathrm{~min}$ and then increased at $10^{\circ} \mathrm{C} / \mathrm{min}$ to $200^{\circ} \mathrm{C}$ and was held for $5 \mathrm{~min}$. The MS NIST Library (http://www.nist.gov/srd/nist1a.cfm) 

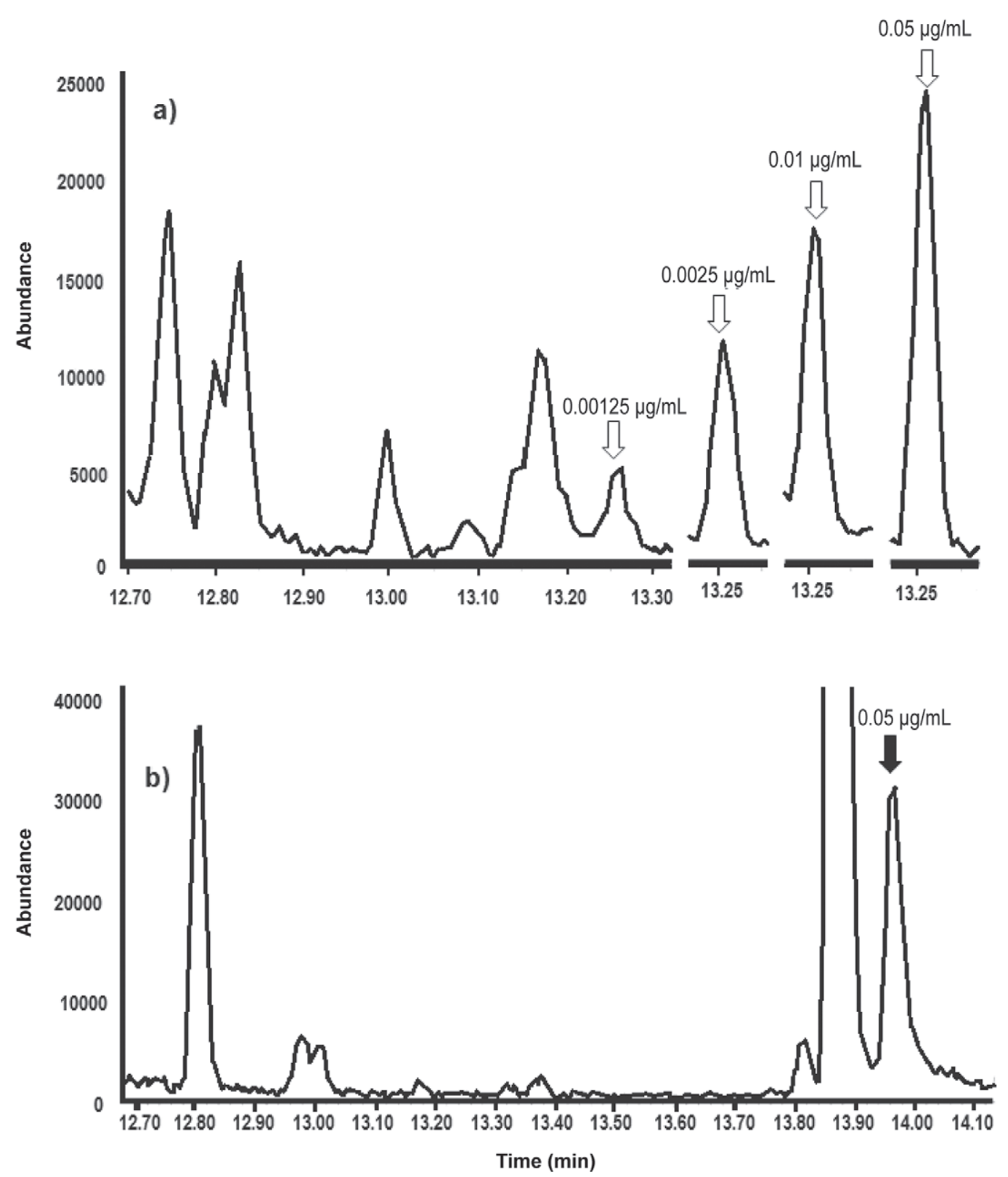

Figure 2. Gas chromatography-MS scans of milk containing (a) E-2-decenal (white arrows) spiked at different concentrations, and (b) tridecane (black arrow) spiked at $0.05 \mu \mathrm{g} / \mathrm{mL}$.

was used for initial peak identification, supported by ion scan profiles. Each milk sample was run in triplicate.

Feeding contaminated silage did not affect silage chemical composition (data not shown) and producers reported no noticeable changes in intake or production when the silage offered was known to be from BMSBinfested corn silage at harvest. Despite the strong odor emanating from the fresh silage when silos were opened, the BMSB odor was not obvious on the farms. For all silage samples collected on farm, $E$-2-decenal was below the level of detection in silage samples collected, despite reports of heavy odor when originally ensiled.

Under the GC-MS conditions used in this study, the E-2-decenal and tridecane spiked into milk eluted at 13.26 and $13.90 \mathrm{~min}$, respectively. Although retentions times were used in this paper, the Kovats retention indices for E-2 decenal and tridecane are 1,262 

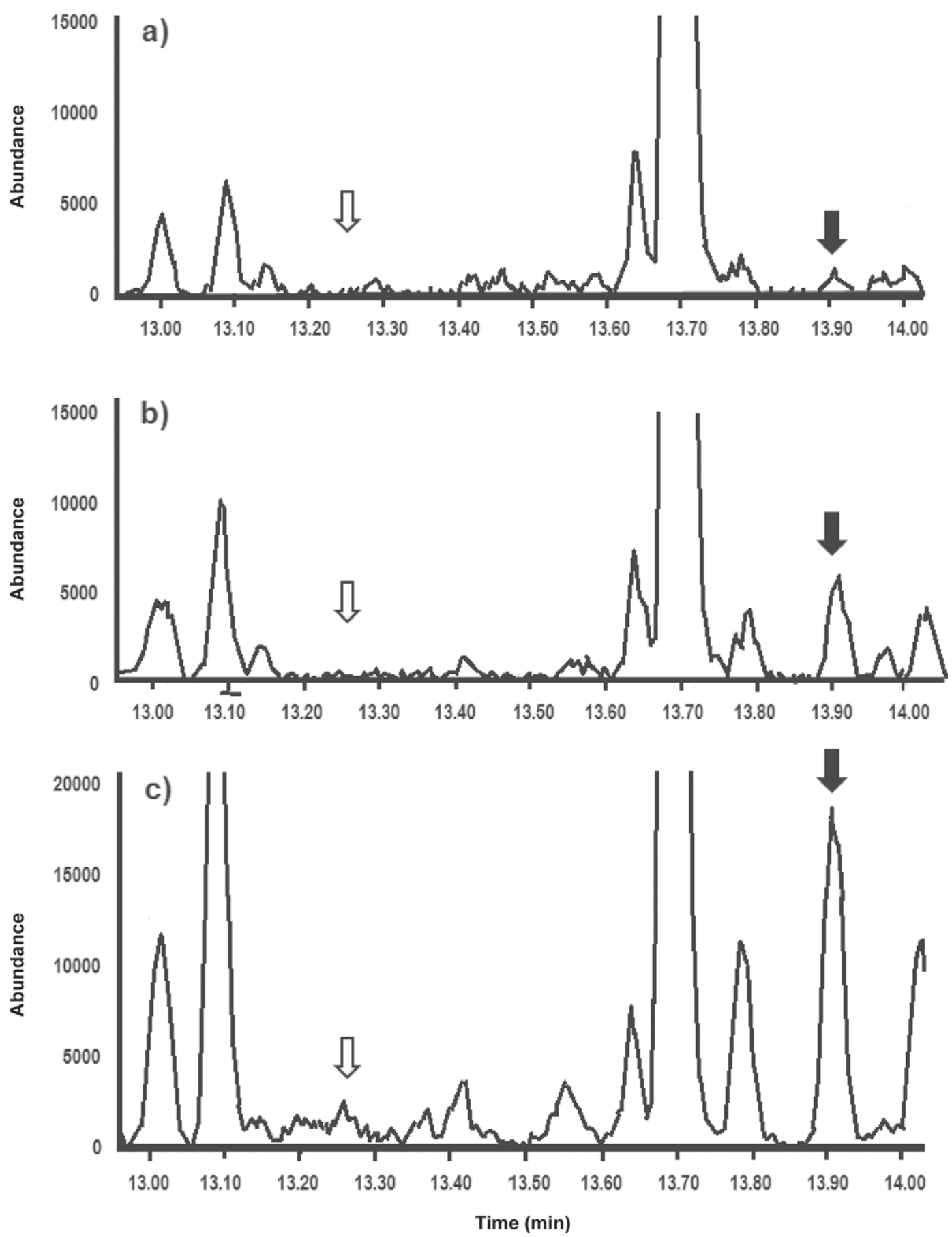

Figure 3. Gas chromatography-MS scans of bovine milk from different herds fed infested silage showing different concentrations of tridecane (black arrow) in the sample from (a) farm C in June, $<0.00125 \mu \mathrm{g} / \mathrm{mL}$; (b) farm C in July, $<0.0025 \mu \mathrm{g} / \mathrm{mL}$; and (c) farm A in August, $<0.01$ $\mu \mathrm{g} / \mathrm{mL}$; white arrow points to where $E$-2-decenal would appear if present.

and 1,300, respectively, when using the DB5 column (http://www.flavornet.org/f_kovats.html). The LOD for both compounds, defined as the lowest concentration with an identifiable peak and a signal:noise ratio of 2 to 3 , was $0.00125 \mu \mathrm{g} / \mathrm{mL}$; the signal:noise ratio was 2.5. The LOQ for both compounds, defined as the lowest concentration of the analyte detectable, was also determined to be $0.00125 \mu \mathrm{g} / \mathrm{mL}$ (see Figure 2a for standard curve for E-2-decenal; similar results were noted for tridecane-Figure $2 \mathrm{~b}$ shows milk spiked at $0.05 \mu \mathrm{g} / \mathrm{mL}$ ). During the 6 mo that milk was collected from the 6 farms, the $E$-2-decenal compound was not 


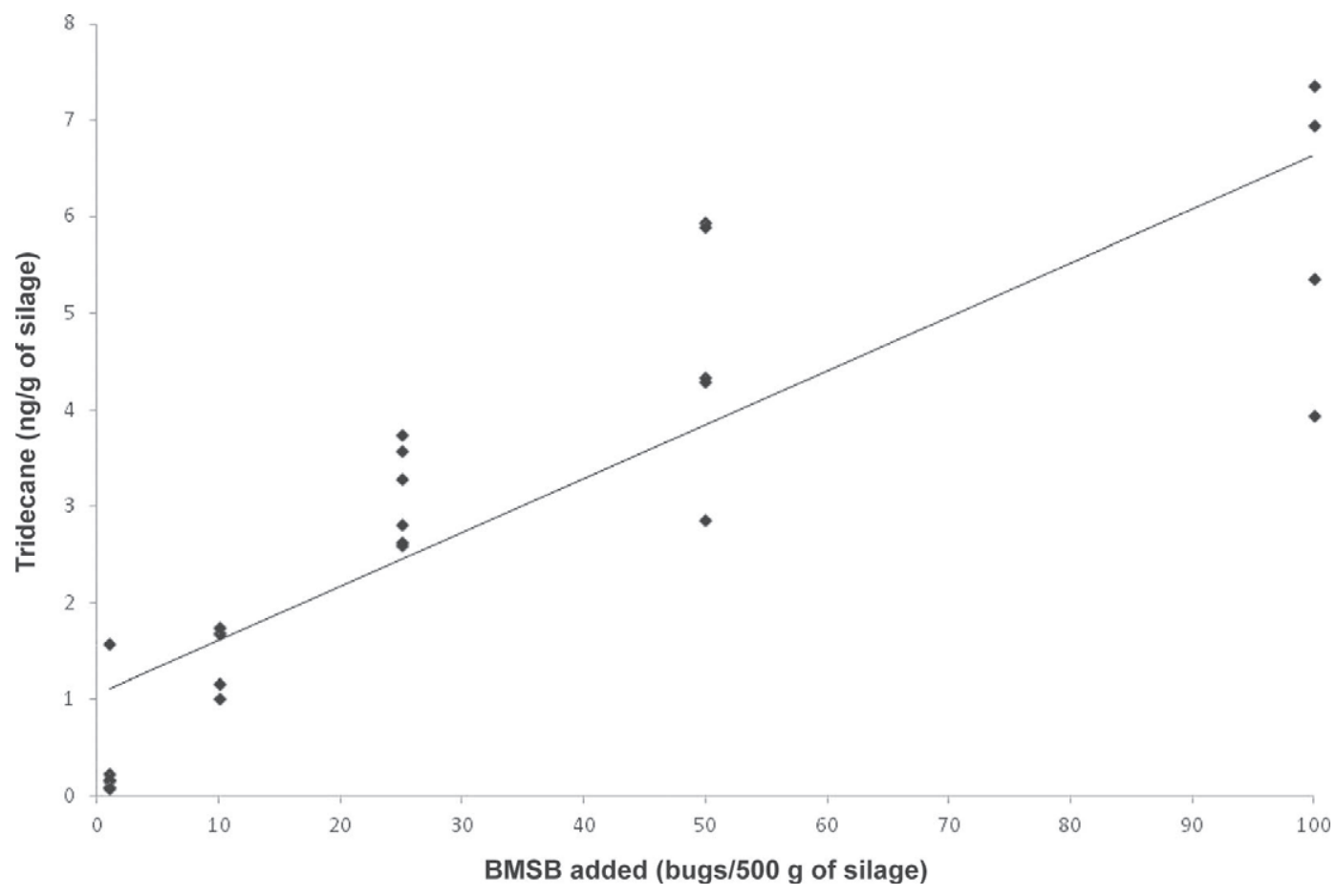

Figure 4. Tridecane concentration (ng/g of silage) as determined by solid-phase microextraction GC-MS in silage from mini silos $(\mathrm{n}=4)$ incubated at room temperature for $90 \mathrm{~d}$ with various concentrations of added brown marmorated stink bugs (BMSB). Linear regression was tridecane $=0.056$ (bugs) $+1.06 ; \mathrm{R}^{2}=0.78$.

detected in any of the milk samples and a background count of $<0.0025 \mu \mathrm{g} / \mathrm{mL}$ of tridecane was detected in the majority of the samples (Figure 3a and 3b). Only a few farms (farm A during August and September, and farms B and E in August) had tridecane concentrations $>0.0025 \mu \mathrm{g} / \mathrm{mL}$; Figure 3c shows farm A in August. The amount of tridecane in the milk was not related to the degree of infestation in the silage fed to the milking herd as farms D, E, and F had the highest load of BMSB in silage but only 1 milk sample from farm E had elevated tridecane levels. It is unclear why farm A had the greatest concentrations of tridecane in 3 of its 6 samples.

Control (unfermented and immediately frozen) minisilos contained measurable E-2-decenal concentrations (mean of $0.194 \mathrm{pg} / \mathrm{g}$ of silage per bug added) but no E-2-decenal could be detected in fermented mini-silos. In contrast, tridecane concentrations did not change with fermentation (Figure 4). Thus, the mini-silo experiment demonstrated that ensiling alone eliminated $E$-2-decenal from BMSB, whereas concentrations of tridecane were unaffected by ensiling. Greater feed quality analysis with more defined controls will ultimately be necessary to assess the effect of high infestations on silage nutritive value. This was not a goal of the current research and samples were not collected with this goal in mind.
Finally, the lactating cows challenged with the highest probable dose of synthetic odor representing $\sim 10,000$ $\mathrm{BMSB} / \mathrm{d}$ or $\sim 100 \mathrm{BMSB}$ per corn stalk at harvest (i.e., the highest reported infestations in western Maryland) exhibited no change in production parameters, including intake, milk production, and milk characteristics. Moreover, ruminally infused $E$-2-decenal and tridecane were not detectable in rumen fluid as soon as $15 \mathrm{~min}$ postdosing and were not detected in milk or urine (data not shown).

None of the milk samples had a noticeable stink bug aroma when opened. The odor threshold for E-2-decenal is reported to be 0.0003 to $0.0004 \mu \mathrm{g} / \mathrm{mL}$ (Fazzalari, 1978; Buttery et al., 1988), which is lower than the concentrations measured in this study $(0.00125 \mu \mathrm{g} / \mathrm{mL})$. Tridecane is considered odorless but a threshold value of $42 \mu \mathrm{g} / \mathrm{mL}$ is given in its material safety data sheet (www.mathesongas.com). Although E-2-decenal and tridecane are the chemicals associated with the BMSB odor, they are also present in very small amounts (parts per billion) in different dairy products. E-2-Decenal, a product of lipid oxidation that is associated with dairy off-flavors such as fatty or green odors, has been reported in oxidized butteroil (Lee et al., 1991), heated milk (Valero et al., 1999), flavored milk drinks (TimmHeinrich et al., 2004), goat cheese (Carunchia Whetstine et al., 2003; Kim et al., 2003; Condurso et al., 
2008), spray-dried skim milk powder (Shiratsuchi et al., 1994), and milk chocolate (Schnermann and Schieberle, 1997). Tridecane, a volatile usually not associated with an odor, has been reported in heated milk (Valero et al., 1999; Solano-Lopez et al., 2005), dry milk powders (Shiratsuchi et al., 1994), sweetened condensed milk (Shimoda et al., 2001), and fresh cheese (Ilicic et al., 2012).

Results from the farm survey portion of the study indicated that, in cows fed infested silage, none of the compounds associated with the stink bug odor were transferred into the milk. Given the decline in $E$-2-decenal concentration due to ensiling and the inability of high doses to be detected in the lactating cow, the risk of deleterious effects on milk quality (off smell or flavor) is unlikely to be from BMSB infestation of feed crops. Moreover, we did not observe an effect on nutrient composition and intake, although further analysis is warranted given the small sample size and lack of control of the extent of contamination level in the silage sampled. Given the loss of E-2-decenal during ensiling, it is unlikely that changes in DMI would occur. Interestingly, tridecane was present and detectable in silage when BMSB were directly added to mini-silos before fermentation; thus, tridecane may serve as an internal marker for assessment of BMSB infestation of corn silage. Finally, the likelihood of transfer of odor compounds into milk from feed contamination by live or dead BMSB is limited given the lack of detection when cows were directly challenged with the highest realistic doses.

\section{ACKNOWLEDGMENTS}

The authors acknowledge the excellent technical support of Donald Carbaugh, Jon Leith, Mike Kemp, Dennis Hucht, Mary Niland, and research support services staff at the USDA-Agricultural Research Service (ARS) in Beltsville, Maryland, and that of Susan Iandola at the USDA-ARS in Wyndmoor, Pennsylvania, who contributed to this project. We also thank our cooperating dairy producers for permitting us to collect milk and silage samples during the study period. Mention of trade names or commercial products in this article is solely for the purpose of providing specific information and does not imply recommendation or endorsement by the USDA or the University of Maryland.

\section{REFERENCES}

Bernon, G. 2004. Biology of Halyomorpha halys, The Brown Marmorated StinkBug(BMSB):FinalReport.AccessedOct.25,2010.http://www. fs.fed.us/ne/newtown_square/publications/technical_reports/ pdfs/2005/ne_gtr332online.pdf.
Buttery, R. G., J. G. Turnbaugh, and L. C. Ling. 1988. Contribution of volatiles to rice aroma. J. Agric. Food Chem. 36: 1006-1009.

Carunchia Whetstine, M. E., Y. Karagul-Yuceer, Y. K. Avsar, and M. A. Drake. 2003. Identification and quantification of character aroma components in fresh Chevre-style goat cheese. J. Food Sci. 68:2441-2447.

Condurso, C., A. Verzera, V. Romeo, M. Ziino, and F. Conte. 2008 Solid-phase microextraction and gas chromatography mass spectrometry analysis of dairy product volatiles for the determination of shelf-life. Int. Dairy J. 18:819-825.

Fazzalari, F. A., ed. 1978. Compilation of odor and taste threshold data. ASTM Data Series DS 48A. American Society for Testing and Materials (ASTM), Philadelphia, PA.

Grob, R. L., and E. F. Barry. 2004. Modern Practice of Gas Chromatography. 4th ed. R. L. Grob and E. F. Barry, ed. John Wiley \& Sons Inc., Hoboken, NJ.

Hamilton, G. C. 2009. Brown marmorated stink bug. Am. Entomol $55: 19-20$.

Hoebeke, E. R., and M. E. Carter. 2003. Halyomorpha halys (Heteroptera: Pentatomidae): A polyphagous plant pest from Asia newly detected in North America. Proc. Entomol. Soc. Wash. 105:225-237.

Ilicic, M. D., S. D. Milanovic, M. D. Caric, K. G. Kanuric, V. R. Vukic, D. V. Hrnjez, and M. I. Ranogajec. 2012. Volatile compounds of functional dairy products. Acta Periodic. Technol. 43:11-19. http://dx.doi.org/10.2298/APT1243011I.

Kim, G.-Y., J.-H. Lee, and D. B. Min. 2003. Study of light-induced volatile compounds in goat's milk cheese. J. Agric. Food Chem. 51:1405-1409.

Lee, S.-R., C. Macku, and T. Shibamoto. 1991. Isolation and identification of headspace volatiles formed in heated butter. J. Agric. Food Chem. 39:1972-1975.

Leskey, T. C., G. C. Hamilton, A. L. Nielsen, D. F. Polk, C. Rodriguez-Saona, J. C. Bergh, D. A. Herbert, T. P. Kuhar, D. Pfeiffer, G. P. Dively, C. R. R. Hooks, M. J. Raupp, P. M. Shrewsbury, G. Krawczyk, P. W. Shearer, J. Whalen, C. Koplinka-Loehr, E. Myers, D. Inkley, K. A. Hoelmer, D.-H. Lee, and S. E. Wright. 2012. Pest status of the brown marmorated stink bug, Halyomorpha halys in the USA. Outl. Pest Manag. 23:218-226.

Maryland Department of Agriculture. 2004-2008. Agriculture in Maryland Summary: 2004-2008. Maryland Department of Agriculture, Annapolis.

Nielsen, A. L., G. C. Hamilton, and D. Matadha. 2008. Developmental rate estimation and life table analysis for Halyomorpha halys (Hemiptera: Pentatomidae). Environ. Entomol. 37:348-355.

Rasmussen, L. E. L., T. D. Lee, A. Zhang, W. L. Roelofs, and G. D. J. Daves. 1997. Purification, identification, concentration and bioactivity of (Z)-7-dodecen-1-yl acetate: Sex pheromone of the female Asian elephant, Elephas maixmus. Chem. Senses 22:417-437.

Schnermann, P., and P. Schieberle. 1997. Evaluation of key odorants in milk chocolate and cocoa mass by aroma extract dilution analyses. J. Agric. Food Chem. 45:867-872.

Shimoda, M., Y. Yoshimura, T. Toshimura, K. Noda, and Y. Osajima. 2001. Volatile flavor compounds of sweetened condensed milk. J. Food Sci. 66:804-807.

Shiratsuchi, H., M. Shimoda, K. Imayoshi, K. Noda, and Y. Osajima. 1994. Volatile flavor compounds in spray-dried milk powder. J. Agric. Food Chem. 42:984-988.

Solano-Lopez, C. E., T. Ji, and V. B. Alvarez. 2005. Volatile compounds and chemical changes in ultrapasteurized milk packaged in polyethylene terephthalate containers. J. Food Sci. 70:C407C412.

Timm-Heinrich, M., N. S. Nielsen, X. Xu, and C. Jacobsen. 2004. Oxidative stability of structured lipids containing C18:0, C18:1, C18:2, C18:3, or CLA in sn2-position as bulk lipids and in milk drinks. Innov. Food Sci. Emerg. Technol. 5:249-261.

USDA-ARS (Agricultural Research Service). 2010. Action plan: Brown marmorated stink bug. USDA-ARS, Kearneysville, WV.

Valero, E., J. Sanz, and I. Martinez-Castro. 1999. Volatile components in microwave- and conventionally-heated milk. Food Chem. 66:333-338. 
Wermelinger, B., D. Wyniger, and B. Forster. 2008. First records of an invasive bug in Europe: Halyomorpha halys Stål (Heteroptera: Pentatomidae), a new pest on woody ornamentals and fruit trees? Bull. Soc. Entomol. Suisse 81:1-9.

Zhang, A., H. T. Facundo, P. S. Robbins, C. E. Linn Jr., J. L. Hanula, M. G. Villani, and W. L. Roelofs. 1994. Identification and synthe- sis of female sex pheromone of oriental beetle, Anomala orientalis (Coleoptera: Scarabaeidae). J. Chem. Ecol. 20:2415-2427.

Zhang, A., C. E. Linn Jr., S. Wright, R. Prokopy, W. Reissig, and W. L. Roelofs. 1999. Identification of a new blend of apple volatiles attractive to the apple maggot, Rhagoletis pomonella. J. Chem. Ecol. 25:1221-1232. 